\title{
Nab-paclitaxel in pretreated metastatic breast cancer: evaluation of activity, safety, and quality of life
}

This article was published in the following Dove Medical Press journal:

OncoTargets and Therapy

\author{
Rossella De Luca' \\ Giuseppe Profita ${ }^{2}$ \\ Giuseppe Cicero' \\ 'Department of Surgical, Oncological \\ and Oral Sciences, Section of \\ Medical Oncology, University of \\ Palermo, Palermo, Italy; ${ }^{2}$ Department \\ of Surgical, Oncological and Oral \\ Sciences, Section of Surgical, \\ University of Palermo, Palermo, Italy
}

Objective: Metastatic breast cancer $(\mathrm{MBC})$ is an incurable disease; the treatment of this disease prolongs survival, improving the quality of life (QoL) with a balance between efficacy and toxicity of the treatment. In recent years, treatment with nab-paclitaxel has improved the already known antitumor activity of conventional paclitaxel, in terms of increased efficacy and better tolerability. The aim of this study was to evaluate nab-paclitaxel in Italian patients with MBC.

Methods: We conducted a retrospective analysis of 90 patients with histologically confirmed diagnosis of MBC. To evaluate the efficacy of nab-paclitaxel, overall survival (OS), progression-free survival (PFS), and overall response rate were the primary endpoints, whereas carbohydrate antigen 15.3 (Ca15.3) reduction, QoL, and tolerability were secondary endpoints.

Results: The median OS was 10.4 months, the median PFS was 6.8 months. A considerable difference $\mathrm{Ca} 15.3$ before and after treatment was observed. Descriptive and regression analyses were done to examine the associations between Ca15.3 response and OS, demonstrating good correlation, revealing that Ca15.3 reduction is an important predictor of OS.

Conclusion: Nab-paclitaxel is an effective and well-tolerated treatment of patients affected by MBC. The drug showed an improved tolerability profile. With all the limitations of the observational nature of our results, nab-paclitaxel has proven to be an effective and safe therapeutic option in patients with MBC.

Keywords: Abraxane ${ }^{\circledR}$, breast cancer metastasis, Ca15.3, pain, overall survival, chemotherapy

\section{Introduction}

Breast cancer is the most common cancer in women. In Italy, breast cancer represents $29 \%$ of all female cancers, with $\sim 50,000$ new cases a year. Furthermore, about $10 \%$ of new breast cancer cases are diagnosed in the metastatic phase. ${ }^{1,2}$ Metastatic breast cancer (MBC), despite the availability of several active endocrine, cytotoxic and targeted agents, remains an incurable disease. ${ }^{3,4}$ The patients with advanced breast cancer frequently receive multiple sequential lines of treatment with palliative therapeutic targets which consist mainly of controlling symptoms, prolonging survival, and improving quality of life (QoL). ${ }^{5}$ In particular, the taxanes (paclitaxel and docetaxel) as single agents and in combination are most frequently used in the treatment of early-stage MBC. ${ }^{6,7}$ The taxanes stabilize microtubules, leading to cell cycle arrest and ultimately cell death. Despite the clinical activity against most cancers, the taxanes are often associated with alopecia, peripheral neuropathy, neutropenia, and serious adverse events of hypersensitivity due to the presence of synthetic solvents
Correspondence: Giuseppe Cicero Department of Surgical, Oncological and Oral Sciences, Section of Medical Oncology, University of Palermo, Via del Vespro, 129, Palermo 90127, Italy Tel +3909123893204

Fax +3909I 6552549

Email giuseppe.cicero@unipa.it
OncoTargets and Therapy 2019:12 1621-1627

(c) (1) (8) ๑ 2019 De Luca et al. This work is published and licensed by Dove Medical Press Limited. The full terms of this license are avalable at https://www.dovepress.com/terms.php cc. hereby accept the Terms. Non-commercial uses of the work are permitted without any further permission from Dove Medical Press Limited, provided the work is properly attributed. For permision for commercial use of this work, please see paragraphs 4.2 and 5 of our Terms (https://www.dovepress.com/terms.php). 
in their composition with negative impact on therapeutic efficacy. ${ }^{8,9}$ Nab-paclitaxel (nanoparticle albumin-boundpaclitaxel; Abraxane ${ }^{\circledR}$ ) is a new paclitaxel developed to avoid hypersensitivity reactions and toxicities associated with solvent-based transport agents, with a more selective and more effective therapeutic activity on tumor cells. ${ }^{10,11}$ It consists of nanoparticles of paclitaxel reversibly linked to human serum albumin of which it uses the natural transport properties. In fact, since the hyper tumor cells produce SPARC (secreted protein acidic and rich in cysteine), to recall albumin for nutritional purposes, the nab-paclitaxel platform exploits the peculiar properties of albumin transport to be conveyed directly into the tumor cells with high drug concentrations and therapeutic doses. ${ }^{12,13}$ Moreover, the nab platform eliminates the need to use toxic solvents thanks to the hydrophobic binding with albumin which also allows the infusion of significantly higher doses of paclitaxel compared to the doses used with standard therapy and with shorter infusion times (30 minutes vs 3 hours, respectively) without premedication. ${ }^{14} \mathrm{Nab}$-paclitaxel has been developed to improve the already known antitumor activity of conventional paclitaxel in terms of greater efficacy and better tolerability. In several phase II and phase III studies, ${ }^{15,16}$ the efficacy and safety of nab-paclitaxel was evaluated in the treatment of patients with $\mathrm{MBC}$, even in women pretreated with anthracyclines, both at the dose of $260 \mathrm{mg} / \mathrm{m}^{2}$ as a 3 -week $\left(\mathrm{q}^{3} \mathrm{w}\right)$ and $150 \mathrm{mg} / \mathrm{m}^{2}$ weekly regimen. These studies showed that nab-paclitaxel was superior to other conventional taxanes in terms of overall response rate (ORR) and progression-free survival (PFS), with favorable toxicity and a favorable safety profile of nab-paclitaxel compared to paclitaxel. Guidelines by the National Comprehensive Cancer Network currently lists the taxanes solvent-based paclitaxel, docetaxel, and nab-paclitaxel as agents recommended for the treatment of recurrent and MBC. ${ }^{17-19}$ According to clinical studies, the main purpose of this study is to evaluate the safety and efficacy of Abraxane ${ }^{\circledR}$ in patients with MBC after first-line treatment.

\section{Study design}

This retrospective study was conducted to evaluate the safety and efficacy of nab-paclitaxel (Abraxane ${ }^{\circledR}$ ) monotherapy in adult patients with progressive $\mathrm{MBC}$ after first-line treatment. Such as previous studies, ${ }^{20-22}$ OS, PFS, and ORR were primary endpoints, the reduction of carbohydrate antigen (Ca15.3), QoL, and tolerability were assessed as the secondary end-point.

\section{Methods}

\section{Patients' selection}

In this retrospective study, 90 patients diagnosed with MBC were enrolled from September 2012 to December 2017 in the Medical Oncology Unit of the University of Palermo and ARNAS Palermo Civico Hospital. This study was approved by ethics committee Policlinico "P. Giaccone" Palermo. The study was conducted according to the Declaration of Helsinki; all patients provided written informed consent before undergoing any study specific procedures. All previously treated patients in the first metastatic line were enrolled in the study and had to satisfy the following inclusion criteria: (1) histologically or cytologically confirmed diagnosis (MBC); (2) not pregnant, not lactating females; (3) performance status between 0 and 2 according to the Eastern Cooperative Oncology Group (ECOG); (4) all enrolled patients had to be progressed after a first-line treatment; (5) cardiac function (ventricular systolic fraction EF >50\%); (6) clinical and radiological evidence of metastatic disease with a number of lesions $\geq 1$ and (7) with the following laboratory results: neutrophils $>2.0 \times 10^{9} / \mathrm{L}$; platelets $>100 \times 10^{9} / \mathrm{L}$; hemoglobin $>10 \mathrm{~g} / \mathrm{dL}$; creatinine $<1 \mathrm{mg} / \mathrm{dL}$, the upper limit of the standard (ULN); creatinine clearance $>60 \mathrm{~mL} / \mathrm{min}$ if creatinine was above the indicated limit; bilirubin $<1 \times \mathrm{ULN}$; aspartate aminotransferase (AST) and alanine aminotransaminase (ALT) $<5 \times \mathrm{ULN}$; and alkaline phosphatase $<5 \times \mathrm{ULN}$ (except in the presence of bone metastases). Patients with asymptomatic central nervous system metastases were approved, and treatment with surgery or radiation therapy of brain lesions should have been completed no more than 3 months before study entry. Patients who were hypersensitive to nab-paclitaxel and its excipients, or to other components of the formulation or with a diagnosis of other malignancies were excluded, except for basal cell carcinoma of the skin, adequately treated, patients with symptomatic brain metastases or patients presenting severe comorbidity not adequately controlled by other ongoing therapies (eg, liver disease, diabetes, infections, heart disease, etc). Other concomitant anticancer therapies were not admitted, and radiotherapy to extracranial sites or hormonal therapy should be terminated at least 1 month before starting nab-paclitaxel treatment.

\section{Evaluation on the response and toxicity}

Evaluation of the response rate in terms of measurable disease reduction according to the response criteria for solid tumor response (RECIST version 1.1) was conducted at the 
beginning of treatment cycle, then every 3 months until disease progression. The spiral computed tomography scan with and without contrast medium was always performed before the beginning of treatment cycle, and then every 3 months until the disease progressed, and whenever an increase of Ca15.3 or a presumed clinical progression was recorded. Total body bone scintigraphy was always performed initially before treatment and then at the discretion of the physician and the characteristics of the patient, every 6 or 12 months. Total body positron emission tomography scan was performed at the discretion of the oncologist physician for any suspected progression of the disease. In the case of brain metastases, a magnetic resonance imaging scan was performed every 12 weeks. Treatment continued until clinical benefit was observed or until treatment was no longer tolerated. Treatment-related toxicity and side effects were assessed at the end of each treatment cycle and reported in line with the Cancer Therapy Evaluation Program, Common Terminology Criteria for Adverse Events (CTCAE), Version 4.0. The Ca15.3 was determined before each treatment cycle and subsequently, every 3 months if positive. The progression of Ca15.3 was considered as: (1) an increase of Ca15.3 $\geq 25 \%$ compared to the baseline values in those patients who did not obtain a significant reduction ( $\geq 50 \%)$ of the serum Ca15.3 levels during treatment; (2) an increase of $\geq 50 \%$ of the lowest level observed in patients who achieved a significant $(\geq 50 \%)$ reduction of serum $\mathrm{Ca} 15.3$ levels during treatment.

\section{Method of administration}

Patients were given nab-paclitaxel (Abraxane ${ }^{\circledR}$; Celgene Corporation, Summit, NJ, USA) at $260 \mathrm{mg} / \mathrm{m}^{2}$ intravenous over 30 minutes every 3 weeks without premedication of steroids or antihistamine or programmed support with granulocyte colony stimulating factor (G-CSF). Treatment was carried out until disease progression or the appearance of unacceptable toxicity. Progressive patients were assigned to start a new treatment. During the entire treatment period, adequate hydration was advised to the patient in order to prevent complications such as renal failure. Treatment was given until disease progression or the development of unacceptable toxicity or patient rejection. Toxic effects of grade 3 or 4 were managed with dose modifications or according to clinical practice procedures. Therapy was postponed for 2 weeks if the neutrophil count was $<1.5 \times 10^{9} / \mathrm{L}$ if the platelet count was $<100 \times 10^{9} / \mathrm{L}$, if the hemoglobin level was $<8.5 \mathrm{~g} / \mathrm{dL}$, or if bilirubin and/or transaminase levels were $>1.5 \times \mathrm{ULN}$. In the case of neutropenia (G2-G3), G-CSF was also administered, under the skin, in advance. If significant anemia occurred (G2-G3) blood transfusions were performed or in less severe cases erythropoietin vials under the skin, and finally for platelet therapy, steroid therapy, or intravenous platelet infusion. Concomitant treatments that did not interfere with the evaluation of nab-paclitaxel, including the use of bisphosphonates or denosumab, could be given at the discretion of the researcher.

\section{Statistical analysis}

The normality of the distribution was checked using the univariate indices of skewness and kurtosis with an acceptance threshold equal to 1 . All variables comply with normality indices. Descriptive statistics were useful to provide a sociodemographic representation and the distribution of all variables. The disease control rate was defined as the percentage of patients with an objective response and/or stable disease lasting $>6$ months. PFS and OS were calculated from the date of the initiation of treatment until the date of the disease progression, or death from any cause for PFS and until the date of the last follow-up, death, or the final follow-up. The date cutoff was December 2017. PFS and OS curves were estimated by using the Kaplan-Meier method. Kaplan-Meier analysis was used to generate survivals curves and estimate median survival with 95\% CIs. The Bravais-Pearson index was used to evaluate the relationship between Ca15.3, OS, and QoL. Statistical analysis was performed using SPSS version 22.0 (IBM Corporation, Armonk, NY, USA).

\section{Results}

The demographic and clinical-pathological characteristics of the 90 patients with MBC are reported in Table 1. At the time of diagnosis, patients were aged between 36 and 83 with a mean age of 59 years, all of them white and most of the patients were post-menopause; 52 patients were ECOG 0, 28 ECOG I and 10 ECOG II, 58 patients were HER2 negative and 32 HER 2 positive, 56 positive hormone receptors and 34 negative receptors, 39 patients were bone metastases, 25 hepatic metastases, 38 pulmonary metastases, 68 lymph node metastases. Eight patients had a triple-negative MBC. Previous anthracyclines were administered to $85.8 \%$ of the patients and $80 \%$ of them had also received previous hormonal therapy. Our analysis shows that the treatment was well tolerated with a good ORR of $22 \%$, with an OS median of 10.4 months and, median PFS of 6.8 months. 
Table I Demographic and clinical characteristics $(\mathrm{N}=90)$

\begin{tabular}{|c|c|}
\hline \multirow[t]{2}{*}{ Characteristics } & Patients \\
\hline & $\mathbf{N}=90$ \\
\hline Mean age (range) & $59(36-83)$ \\
\hline \multicolumn{2}{|l|}{ Menopausal status (\%) } \\
\hline Postmenopausal & $61(68)$ \\
\hline Premenopausal & $29(32)$ \\
\hline \multicolumn{2}{|l|}{ Previous treatment } \\
\hline \multicolumn{2}{|c|}{$\begin{array}{l}\text { HER2+ } \\
\text { Anthracycline, cyclophosphamide and trastuzumab }\end{array}$} \\
\hline \multicolumn{2}{|l|}{ HER2- } \\
\hline \multicolumn{2}{|c|}{ Anthracycline and cyclophosphamide } \\
\hline \multicolumn{2}{|l|}{ Triple negative } \\
\hline \multicolumn{2}{|l|}{ Taxolo and Avastin } \\
\hline \multicolumn{2}{|c|}{ ECOG performance status (\%) } \\
\hline 0 & $52(58)$ \\
\hline 1 & $28(3 I)$ \\
\hline 2 & $10(I I)$ \\
\hline \multicolumn{2}{|l|}{ Median Ca I5.3 } \\
\hline$<35 \mathrm{ng} / \mathrm{mL}$ cutoff (range) & $190(180-300)$ \\
\hline \multicolumn{2}{|l|}{ Metastatic site (\%) } \\
\hline Liver & $25(28)$ \\
\hline Lung & $38(42)$ \\
\hline Bone & $39(43)$ \\
\hline Lymph nodes & $68(75.5)$ \\
\hline
\end{tabular}

Abbreviation: ECOG, Eastern Cooperative Oncology Group.

The response rate of Ca15.3-8 weeks after the end of treatment was $>50 \%$ to correlate with improved survival. Treatment with Abraxane ${ }^{\circledR}$ was well tolerated and resulted in a good level of disease control ( $\mathrm{RC}+\mathrm{PR}+\mathrm{DS}>50 \%$ ) and the median duration of the response was 6 months. After a mean follow-up duration of 9.2 months (range: 5.2-15.2 months), $1 \%$ of patients had a complete response (RC) the $19 \%$ had a PR, 34\% had a disease stabilization (DS), 38\% showed disease progression (PD), and $8 \%$ unable to determine. The patients with an objective response and stable disease show the clinical benefit rate. The ORR were slightly higher in HER2-negative (22\%), ER and PR positive 20\%-22\% ER and PR negative $18 \%-20 \%$ the HER 2 positive (20\%) reduced the clinical efficacy induced by nab-paclitaxel.

\section{OS and PFS analysis}

Among the 90 patients enrolled for this study, the interim survival analysis (last follow-up in December 2017) showed a value of 10.4 months (95\% CI: 8.1-14.6 months) (Figure 1). Median PFS was 6.8 months (95\% CI: 5.9-11.6 months) (Figure 2). This variable is associated positively with the

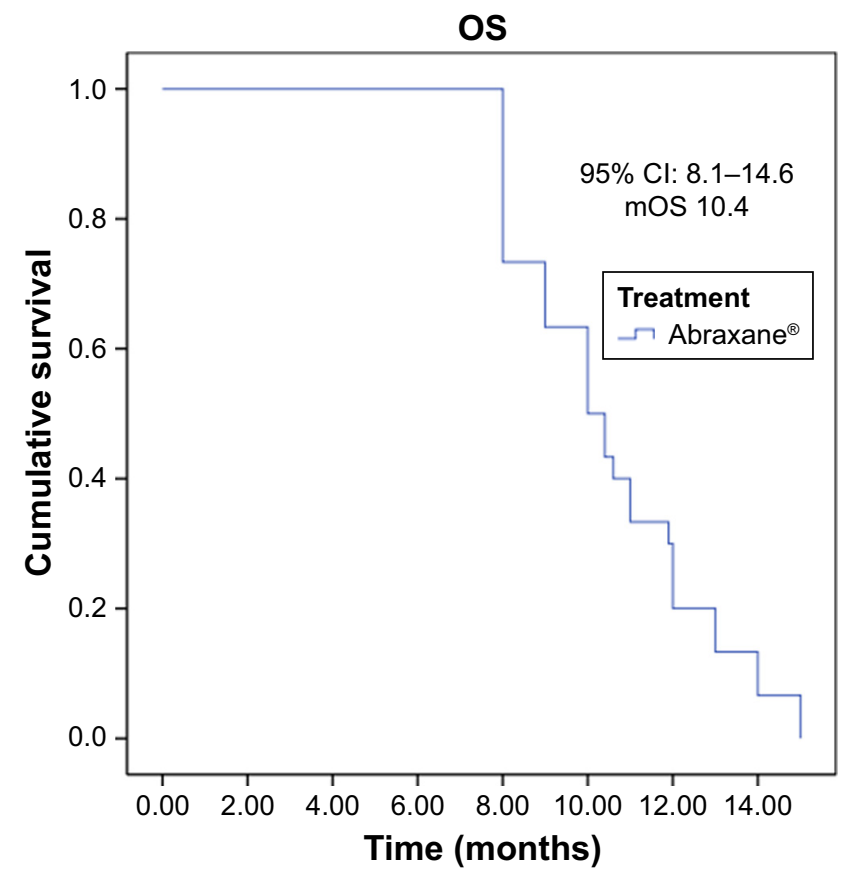

Figure I Kaplan-Meier plot of median OS (interim analysis) ( $\mathrm{N}=90)$. Abbreviations: mOS, median overall survival; OS, overall survival.

QoL, in fact, by means of the Bravais-Pearson index, a good correlation between these two variables has been demonstrated with an $r(95 \% \mathrm{CI})$ value of 0.58 and $0.59(0.28-0.86)$, $P=0.002$ (Table 2).

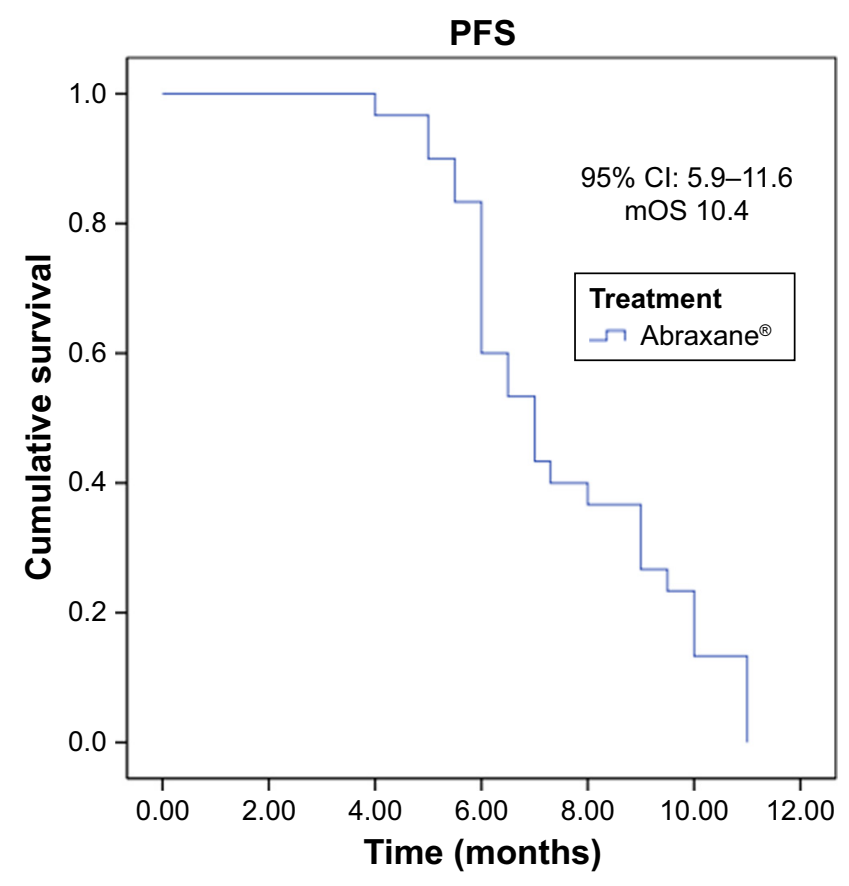

Figure 2 Kaplan-Meier plot of Median PFS (interim analysis) ( $\mathrm{N}=90$ ). Abbreviations: mPFS, median progression-free survival; PFS, progression-free survival. 
Table 2 Pearson's correlation among Cal5.3, OS, and QoL $(\mathrm{N}=90)$

\begin{tabular}{|l|l|l|l|l|}
\hline Comparisons & Ca I5.3 & OS & QoL & P-value \\
\hline Ca I5.3 & I & $-0.59 *$ & $-0.58^{*}$ & 0.002 \\
\hline OS & $-0.59 *$ & I & $0.59 *$ & 0.002 \\
\hline QoL & $-0.58^{*}$ & $0.59 *$ & I & 0.005 \\
\hline
\end{tabular}

Note: $* P<0.01$.

Abbreviations: Cal5.3, carbohydrate antigen 15.3; OS, overall survival; QoL, quality of life.

\section{Cal 5.3 reduction}

The analysis of Ca15.3 values made it possible to observe that after treatment with Abraxane ${ }^{\circledR},>50 \%$ of patients reported a reduction in initial values and we showed that this reduction was linked to an increase in OS. Therefore, the Ca15.3 response may be an important predictor of OS augmentation with a positive correlation obtained between the Ca15.3 response with $\mathrm{OS} \beta=0.365,(P<0.01)$.

\section{Tolerability}

No patient died due to treatment with nab-paclitaxel. Tolerability was assessed based on common terminological criteria for adverse events at the National Cancer Institute (version 4.0). Overall, nab-paclitaxel therapy was well tolerated, the dose reductions, and dose delays were infrequent $(3 \%-5 \%)$. All 90 patients in the ITT population were included in the safety analysis. No severe (grade 3 or 4) treatment-related hypersensitivity reactions occurred in any of the patients in the group despite the absence of premedication. Treatment-related grade 3 sensory neuropathy occurred more frequently, but these episodes improved with interruption of treatment. No episodes of motor neuropathy or grade 4 sensory neuropathy were reported. The incidence of treatment-related grade 4 neutropenia (based on the central laboratory test values) was $9 \%$ which required the use of G-CSF also as prophylaxis of $8 \%$ a grade G2-G3 platelet which required the use of corticosteroids and $15 \%$ had anemia (G2-G3) that required the administration of erythropoietin toxicity was assessed through clinical evaluation, total blood cells and complete serum chemistry and were classified according to national criteria of common toxicity. Events associated with the treatment of toxicity and side effects are described respectively in Table 3. No patient discontinued treatment due to severe side effects.

\section{QoL}

QoL was measured using the questionnaire of the European Organization for the Research and Treatment of Quality of
Table 3 Adverse events grade with Common Terminology Criteria for Adverse Events, version $4.0(\mathrm{~N}=90)$

\begin{tabular}{|l|l|}
\hline Adverse event & Patients (\%) \\
\hline \multicolumn{2}{|l|}{ Hematological } \\
\hline Grade 2 anemia & 36 \\
\hline Grade 3 anemia & 64 \\
\hline Grade 2 neutropenia & 27 \\
\hline Grade 3 neutropenia & 72 \\
\hline Febrile neutropenia & 37 \\
\hline Grade I-2 thrombocytopenia & 6 \\
\hline Nonhematological & \multicolumn{2}{|l|}{} \\
\hline Grade 3 asthenia & 30 \\
\hline Grade 2-3 peripheral neuropathy & 45 \\
\hline Grade 3 stomatitis & 10 \\
\hline Alopecia & 90 \\
\hline Grade 2 skin reactions & 3 \\
\hline Grade 2-3 diarrhea & 7 \\
\hline
\end{tabular}

Life C30 (EORTC-QoL-C30) Version 3.023 and was analyzed as a change from baseline at each cycle. With a score of 45 $(0-100)$ and a global health status/QoL scales. The QoL showed an improvement in the treatment. Scores on the functional scales of the EORTC QLQ-C30 ranged indicating that the patients' QoL was sufficient overall (Table 4). An improvement in QoL was also identified with a reduction in pain symptoms.

\section{Discussion}

Breast cancer is the most common cancer in the female population and is the leading cause of cancer death in women

Table 4 Mean and SD of the EORTC-QLQ-C30 (N=90)

\begin{tabular}{|l|l|}
\hline Quality of life & Mean (SD) \\
\hline Physical functioning & $78.3(17.5)$ \\
\hline Role functioning & $69.9(30.6)$ \\
\hline Emotional functioning & $83.3(24.4)$ \\
\hline Cognitive functioning & $81.6(28.5)$ \\
\hline Social functioning & $79.4(27.9)$ \\
\hline Global health/QoL & $45.3(21.6)$ \\
\hline Insomnia & $26.4(28.8)$ \\
\hline Fatigue & $62.3(25.3)$ \\
\hline Pain & $18.8(27.4)$ \\
\hline Dyspnea & $18.4(36.1)$ \\
\hline Constipation & $26.5(16.9)$ \\
\hline Appetite loss & $28.7(29.2)$ \\
\hline Diarrhea & $52.4(19.5)$ \\
\hline Nausea, vomiting & $39.3(21.4)$ \\
\hline Financial difficulties & $47.7(29.7)$ \\
\hline
\end{tabular}

Abbreviations: EORTC-QLQ-C30, European Organization for the Research and Treatment of Quality of Life C30; QoL, quality of life. 
in more developed countries, despite progress in screening and treatment. In Italy about $7 \%$ of women have an MBC at the first diagnosis, and the risk of relapse at ten years is about $70 \%$ in women with positive histological lymph nodes. ${ }^{24}$ The primary goals of chemotherapy treatment in MBC patients are to prolong survival and improve QoL and control symptoms. This study aims to evaluate the efficacy of nab-paclitaxel (Abraxane ${ }^{\circledR}$ ) as monotherapy in Italian patients with progressing MBC after a first-line chemotherapy regimen. ${ }^{25}$ Taxanes have been widely proven to be among the most active cytotoxic drugs for the treatment of breast cancer and, since their advent, have provided a new chemotherapy option in the treatment of patients with MBC. ${ }^{26}$ The new solvent-free formulation of paclitaxel, nab-paclitaxel, has shown good safety and a good efficacy profile. ${ }^{27,28}$ Our results, even if with a limited number of patients, are in agreement with the clinical evidence reported in the literature and result in a recent and updated analysis of the survival data of the Phase III trial of nanoparticle albumin-bound paclitaxel compared with polyethylated castor oil-based paclitaxel in women with breast cancer by which it was confirmed that the treatment with nab-paclitaxel determines an improvement in the OS rate, and PFS associated with a reduction of the values of Ca15.3. In particular, the reduction of Ca15.3 was $>54 \%$, and we have also shown that this reduction was linked to an increase in the OS. Therefore, the Ca15.3 response can be an important predictor of OS augmentation. Furthermore, our analysis shows that this treatment was well tolerated and associated with a good objective response rate, only $9 \%$ of patients developed severe neutropenia (grade 3 CTCAE). This result is in agreement with the published data showing a greater risk of mild-moderate side effects associated with nab-paclitaxel treatment. In our study, we also found a significant impact of nab-paclitaxel on pain reduction and this was linked to better survival and improvement of QoL. ${ }^{29}$ We realize, however, that despite our results being in line with those reported in the literature, there are limits that must be taken into consideration, related for example, to the evaluation of the response and to the small size of the sample.

\section{Conclusion}

Nab-paclitaxel monotherapy is effective, well tolerated, safe, and the toxicity associated with treatment is acceptable. Response rates, safety, and improvement of the QoL are satisfactory. Based on these results, we can conclude that nab-paclitaxel treatment every 3 weeks is a valuable regimen for the progressive form of MBC. Furthermore, nabpaclitaxel shows several advantages over existing taxanes, facilitating drug administration and improving patient acceptance, particularly due to the absence of premedication with corticosteroids or prolonged infusions or special intravenous infusion sets. The use of nab-paclitaxel monotherapy in MBC is supported by clear efficacy data, and post-approval clinical studies have confirmed its role in the treatment of MBC. In conclusion, this innovative formulation of albumin-bound paclitaxel has a significant antitumor activity and a manageable safety profile in patients pretreated after at least one line of chemotherapy; this cytotoxic drug was shown to be aggressive in breast cancer, such as triple-negative tumors. Our results, even with a limited number of patients, are in agreement with the clinical evidence reported in the literature.

\section{Disclosure}

The authors report no conflicts of interests in this work.

\section{References}

1. Ferlay J, Steliarova-Foucher E, Lortet-Tieulent J, et al. Cancer incidence and mortality patterns in Europe: estimates for 40 countries in 2012. Eur J Cancer. 2013;49(6):1374-1403.

2. Yersal O, Barutca S. Biological subtypes of breast cancer: prognostic and therapeutic implications. World J Clin Oncol. 2014;5(3):412-424.

3. Meraviglia S, Eberl M, Vermijlen D. In vivo manipulation of $\mathrm{V} \gamma 9 \mathrm{~V} \delta 2$ $T$ cells with zoledronate and low-dose interleukin-2 for immunotherapy of advanced breast cancer patients. Clin Exp Immunol. 2010;161(2): 290-297.

4. National Cancer Institute - Surveillance, Epidemiology and End Results [homepage on the Internet]. SEER stat fact sheets: breast. SEER;

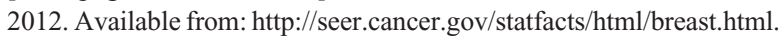
Accessed July 27, 2012.

5. Duffy MJ, Harbeck N, Nap M, et al. Clinical use of biomarkers in breast cancer: updated guidelines from the European Group on Tumor Markers (EGTM). Eur J Cancer. 2017;75:284-298.

6. Cardoso F, Bedard PL, Winer EP, et al. International guidelines for management of metastatic breast cancer: combination vs sequential singleagent chemotherapy. J Natl Cancer Inst. 2009;101(17):1174-1181.

7. Cardoso F, Costa A, Senkus E, et al. 3rd ESO-ESMO international consensus guidelines for advanced breast cancer (ABC 3). Breast. 2017;31:244-259

8. Piccart-Gebhart MJ, Burzykowski T, Buyse M, et al. Taxanes alone or in combination with anthracyclines as first-line therapy of patients with metastatic breast cancer. J Clin Oncol. 2008;26(12):1980-1986.

9. Nabholtz J-M, Falkson C, Campos D, et al. Docetaxel and doxorubicin compared with doxorubicin and cyclophosphamide as first-line chemotherapy for metastatic breast cancer: results of a randomized, multicenter, phase III trial. J Clin Oncol. 2003;21(6):968-975.

10. Piccart-Gebhart MJ, Burzykowski T, Buyse M, et al. Taxanes alone or in combination with anthracyclines as first-line therapy of patients with metastatic breast cancer. J Clin Oncol. 2008;26(12):1980-1986.

11. Ravdin PM, Burris HA, Cook G, et al. Phase II trial of docetaxel in advanced anthracycline-resistant or anthracenedione-resistant breast cancer. J Clin Oncol. 1995;13(12):2879-2885.

12. Miele E, Spinelli GP, Miele E, Tomao F, Tomao S. Albumin-bound formulation of paclitaxel (Abraxane ABI-007) in the treatment of breast cancer. Int J Nanomedicine. 2009;4:99-105.

13. European Medicines Agency. Abraxane summary of product characteristics. EMA; 2008. Available from: http://www.ema.europa.eu/ema/index. jsp?curl=pages/medicines/human/medicines/000778/human_med_000620. jsp\&mid=WC0b01ac058001d124. Accessed December 6, 2018. 
14. Ghersi D, Willson ML, Chan MMK, et al. Taxane-containing regimens for metastatic breast cancer. Cochrane Database Syst Rev. 2015;6: CD003366.

15. Gradishar WJ. Albumin-bound paclitaxel: a next-generation taxane. Expert Opin Pharmacother. 2006;7(8):1041-1053.

16. Gradishar WJ, Tjulandin S, Davidson N. Superior efficacy of albuminbound paclitaxel, ABI-007, compared with polyethylated castor oilbased paclitaxel in women with metastatic breast cancer: results of a phase III trial. J. Clin. Oncol. 2005;23:7794-7803.

17. Cortazar P, Justice R, Johnson J, Sridhara R, Keegan P, Pazdur R. US Food and Drug Administration approval overview in metastatic breast cancer. J Clin Oncol. 2012;30(14):1705-1711.

18. Ibrahim NK, Desai N, Legha S, et al. Phase I and pharmacokinetic study of ABI-007, a Cremophor-free, protein-stabilized, nanoparticle formulation of paclitaxel. Clin Cancer Res. 2002;8(5):1038-1044.

19. Gradishar WJ, Krasnojon D, Cheporov S, et al. Significantly longer progression-free survival with nab-paclitaxel compared with docetaxel as first-line therapy for metastatic breast cancer. J Clin Oncol. 2009; 27(22):3611-3619.

20. Cicero G, De Luca R, Dieli F. Efficacy and safety of the oral multikinase regorafenib in metastatic colorectal cancer. Oncology. 2017;93(6): 354-358.

21. Cicero G, De Luca R, Blasi L, et al. Treatment with abiraterone in metastatic castration-resistant prostate cancer patients progressing after docetaxel: a retrospective study. Anticancer Drugs. 2017;28(9): 1047-1052.

22. De Luca R, Costa RP, Tripoli V, Murabito A, Cicero G. The clinical efficacy of radium-223 for bone metastasis in patients with castrationresistant prostate cancer: an Italian clinical experience. Oncology. 2018;94(3):161-166.
23. Coates A, Porzsolt F, Osoba D. Quality of life in oncology practice: prognostic value of EORTC QLQ-C30 scores in patients with advanced malignancy. Eur J Cancer. 1997;33(7):1025-1030.

24. Sparreboom A, Scripture CD, Trieu V, et al. Comparative preclinical and clinical pharmacokinetics of a cremophor-free, nanoparticle albuminbound paclitaxel (ABI-007) and paclitaxel formulated in Cremophor (Taxol). Clin Cancer Res. 2005;11(11):4136-4143.

25. Ibrahim NK, Samuels B, Page R, et al. Multicenter phase II trial of ABI-007, an albumin-bound paclitaxel, in women with metastatic breast cancer. J Clin Oncol. 2005;23(25):6019-6026.

26. O'Shaughnessy J, Gradishar WJ, Bhar P, Iglesias J. Nab-paclitaxel for first-line treatment of patients with metastatic breast cancer and poor prognostic factors: a retrospective analysis. Breast Cancer Res Treat. 2013;138(3):829-837.

27. Mirtsching B, Cosgriff T, Harker G, Keaton M, Chidiac T, Min M. A phase II study of weekly nanoparticle albumin-bound paclitaxel with or without trastuzumab in metastatic breast cancer. Clin Breast Cancer. 2011;11(2):121-128.

28. Megerdichian C, Olimpiadi Y, Hurvitz SA. Nab-paclitaxel in combination with biologically targeted agents for early and metastatic breast cancer. Cancer Treat Rev. 2014;40(5):614-625.

29. Palumbo R, Sottotetti F, Bernardo A. Targeted chemotherapy with nanoparticle albumin-bound paclitaxel (nab-paclitaxel) in metastatic breast cancer: which benefit for which patients? Ther Adv Med Oncol. 2016;8(3):209-229.
OncoTargets and Therapy

\section{Publish your work in this journal}

OncoTargets and Therapy is an international, peer-reviewed, open access journal focusing on the pathological basis of all cancers, potential targets for therapy and treatment protocols employed to improve the management of cancer patients. The journal also focuses on the impact of management programs and new therapeutic agents and protocols on

\section{Dovepress}

patient perspectives such as quality of life, adherence and satisfaction. The manuscript management system is completely online and includes a very quick and fair peer-review system, which is all easy to use. Visit http://www.dovepress.com/testimonials.php to read real quotes from published authors. 